\title{
Patterns of dyslipidemia in young patients with seronegative spondyloarthropathies without cardiovascular diseases
}

\author{
Patrycja Ozdowska ${ }^{1}$, Ilona Kowalik² ID , Krzysztof Sadowski² ID , Hanna Szwed ${ }^{2}$ ID , Piotr Głuszko ID \\ Robert Rupiński $^{4}$, Brygida Kwiatkowska ${ }^{5}$ ID , Katarzyna Sikorska-Siudek ${ }^{4}$ ID , Rafał Dąbrowski ${ }^{2}$ ID \\ ${ }^{1} 2^{\text {nd }}$ Department of Coronary Artery Disease, National Institute of Cardiology, Warsaw, Poland 2Department of Coronary Artery \\ Disease and Cardiac Rehabilitation, National Institute of Cardiology, Warsaw, Poland \\ ${ }^{3}$ Rheumatology Clinic and Polyclinic, National Geriatrics, Rheumatology and Rehabilitation Institute, Warsaw, Poland \\ ${ }^{4}$ National Geriatrics, Rheumatology and Rehabilitation Institute, Warsaw, Poland \\ ${ }^{5}$ Clinic of Early Arthritis, National Geriatrics, Rheumatology and Rehabilitation Institute, Warsaw, Poland
}

\begin{abstract}
Objectives: Patients with seronegative spondyloarthritis (SpA) - psoriatic arthritis (PsA) and ankylosing spondylitis (AS) - have a higher risk of cardiovascular morbidity and mortality. The aim of the present study was to evaluate the incidence and type of dyslipidemia, a potent atherosclerosis risk factor, in SpA patients.

Material and methods: It was a two-center, case-control study. Patients diagnosed with PSA and AS aged 23-60 years, with disease duration < 10 years, were enrolled. The inflammatory activity, serum levels of C-reactive protein (CRP) and lipid profile were evaluated in each patient. In patients $>40$ years old, the 10-year risk of fatal cardiovascular disease (CVD), using Systematic Coronary Risk Evaluation (SCORE), was estimated.

Results: In total 79 patients with SpA were included in the study, with PsA diagnosed, $n=39$ (mean age $45.1 \pm 9.6$ years; $21,53.9 \%$, women), and with AS diagnosed, $n=40$ (age $40.3 \pm 9.5 ; 12.3 \%$, women), control group (CG): $n=88$ (age $42.3 \pm 8.1 ; 42,47.7 \%$ women). Based on the interview and laboratory tests, dyslipidemia was diagnosed in 19 (47.5\%) patients with AS and in 28 (71.8\%) patients with PSA. Most patients had hypercholesterolemia or mixed hyperlipidemia. Types of dyslipidemia were similar. In SpA patients (PsA and AS), the level of triglycerides (TG) and atherogenic index (AI) were significantly higher than in the CG, respectively TG in SpA: 116 (83-156) and in the CG: 91.2 (72.6-134.6) $\mathrm{mg} / \mathrm{dl}, p=0.0182$; Al in SpA: $3.77 \pm 1.26$ and in the CG: $2.58 \pm 1.27, p<0.0001$.

The low-density cholesterol (LDL) level was significantly lower in SpA patients than in the CG, SpA: $109.1 \pm 29.4$ vs. CG: $125.2 \pm 35.9 \mathrm{mg} / \mathrm{dl}, p=0.0023$. There was a strong negative correlation between CRP levels and HDL cholesterol levels in patients with PsA, rho $=0.42, p=0.0132$. Mean SCORE values were $2.33 \%$ in PSA patients and $2.38 \%$ in AS patients, which results in moderate 10-year risk of death from CVD.

Conclusions: In young patients with spondyloarthropathies, inflammatory factors significantly influence dyslipidemia patterns, which result in higher TG and lower LDL cholesterol levels. In patients with PsA, dyslipidemia was diagnosed more often than in patients with AS.
\end{abstract}

Key words: cardiovascular diseases, dyslipidemia, seronegative spondyloarthropathies.

\section{Introduction}

Psoriatic arthritis (PsA) and ankylosing spondylitis (AS) are included in spondyloarthritis (SpA) or rheumatic diseases associated with spondylitis [1]. Their occurrence is a factor increasing the risk of cardiovascular disease (CVD) and mortality due to cardiological causes [2-4]. Chronic inflammation causes functional and structural changes not only in the musculoskeletal system but also

\section{Address for correspondence:}

Krzysztof Sadowski, Department of Coronary Artery Disease and Cardiac Rehabilitation, National Institute of Cardiology, 42 Alpejska St., 04-628 Warsaw, Poland, e-mail: ksadowski@ikard.pl

Submitted: 01.09.2021; Accepted: 01.10.2021 
in internal organs. Higher serum levels of inflammation markers are found in the serum of patients with PsA and AS than in the general population. Dyslipidemia plays an essential role in the pathogenesis of CVD in patients with PsA and AS. On the one hand, it is the effect of an inflammatory process promoted by pro-inflammatory cytokines, such as TNF- $\alpha$ and interleukins 6, 17 and 23. On the other, the progressive dysfunction of the musculoskeletal system leads to reduced physical activity and predisposes to obesity. In the group of patients with PsA and AS, the incidence of dyslipidaemia is 1.2 times higher compared to the general population [4]. Characteristic is the reduction in total (CHOL) and high-density $(\mathrm{HDL})$ cholesterol and an increase in triglyceride (TG) levels [5-7]. In the cases of active AS, lower total cholesterol and significantly lower HDL cholesterol were found, which increases the atherogenicity index $(\mathrm{Al})[5,7]$.

The qualitative composition of $\mathrm{HDL}$ particles also changes. Triglyceride and low-density cholesterol (LDL) levels remain elevated or lowered in patients with AS depending on the studied group and disease activity $[8,9]$. The inflammatory pathogenesis of dyslipidemia may be supported by the fact that in patients treated with TNF- $\alpha$ inhibitors, in addition to reducing inflammation parameters, an increase in HDL cholesterol levels and changes in its composition have also been observed $[5,10]$. Studies conducted in patients with rheumatic arthritis show that elevated CRP levels promote adverse changes in lipoprotein composition, including lowering HDL cholesterol and its unfavorable modification. In patients with AS and with elevated CRP, apolipoprotein A1, with antiatherosclerotic properties, is replaced by amyloid A, which may affect the development of atherosclerotic lesions [5]. All this leads to progressive endothelial dysfunction [11].

The aim of the present study was to evaluate the incidence and type of dyslipidemia in young SpA patients with short disease duration.

\section{Material and methods}

It was a two-center, prospective case-control study conducted in the period October 01, 2013-September 30, 2014. The study included patients with PsA and AS. Diagnoses were based on ASAS criteria (Assessment in Ankylosing Spondylitis), modified New York criteria for AS and CASPAR for PSA [12-15]. The patients were treated in the National Institute of Geriatrics, Rheumatology, and Rehabilitation in Warsaw. The inclusion criteria were: informed consent to participate in the study, women and men with PsA and AS aged 23-60 years in whom the duration of the underlying disease from the time of the diagnosis did not exceed ten years.
Patients with known or suspected CVD, diabetes mellitus, atrial fibrillation, hypo- or hyperthyroid status, oncological diseases, and pregnant women were excluded from the study. The control group (CG) consisted of patients matched for age, gender, body mass index (BMI), smoking status, history of hypertension and dyslipidemia, with no rheumatological diseases. Eighty-eight patients were included in the CG. In addition, the duration and activity of spondyloarthropathy as determined by the BASDAI (Bath Ankylosing Spondylitis Disease Activity Index) and ASDAS-CRP (Ankylosing Spondylitis Disease Activity Score) scales were recorded in each patient with SpA.

Disease activity was divided based on the calculated BASDAI and ASDAS-CRP indices, according to the current rheumatological guidelines, into very high when ASDAS-CRP was above 3.5 points; high when ASDAS-CRP was above 2.1 points and BASDAI above 4 points; moderate when ASDAS-CRP was above 1.3 points; and low (an inactive inflammatory process), ASDAS $<1.3$ and BASDAI $<4$ points. Fasting blood samples were taken from each patient for lipid parameters and inflammation markers.

Castelli's atherogenicity index (AI) was calculated from the ratio total cholesterol/HDL value; the standard value in men is < 4.5, in women < 4.0. Each patient over 40 years of age was subjected to an individual assessment of the total risk of death from cardiovascular causes within ten years (SCORE, Systematic COronary Risk Evaluation) according to the cardiovascular risk assessment scale. For this purpose, the program of the European Society of Cardiology was used (algorithm in force in Poland, prepared for the high-risk population, accepted by the Polish Society of Cardiology) [16].

The overall risk was assessed as very high when the calculated SCORE was at least 10\%, high when the SCORE was above $5 \%$, moderate when the SCORE was $1-5 \%$, and low when the SCORE was below $1 \%$.

The study was supported by a State Committee for Scientific Research grant and carried out at the National Institute of Cardiology, Warsaw, and at the National Institute of Geriatrics, Rheumatology and Rehabilitation, Warsaw, between October 2013 and September 2014 (9.37/III/13). The design and protocol of the study were approved by the institutional review board (IK-NP-0071-1/2013).

\section{Statistical analysis}

All results for categorical variables were presented as counts and percentages and for continuous variables as mean and standard deviation (SD) or median and lower and upper quartiles [Q1:25 th, Q2:75 th percentiles]. The chisquare independence test or Fisher exact test was used for comparison of categorical variables. The differences be- 
tween continuous variables were tested by Student t-test (for two independent samples, normally distributed data), or in the case of skewed distribution, the non-parametric the Mann-Whitney $U$ test. The significance of differences between the three groups was verified by parametric ANOVA or non-parametric ANOVA (Kruskal-Wallis test) as appropriate. All hypotheses were two-tailed with a 0.05 type I error. All statistical analyses were performed using SAS statistical software, version 9.4 (SAS Institute, Cary, NC, USA).

\section{Results}

Total of 79 patients with SpA were included in the study: with PsA diagnosed, $n=39$ (mean age $45.1 \pm 9.6$ years; $21,53.9 \%$, women and with AS diagnosed, $n=40$ (age $40.3 \pm 9.5 ; 12.3 \%$, women), CG: $n=88$ (age $42.3 \pm 8.1$; $42,47.7 \%$ women). The median duration of illness was 18 (10-36) months in the PsA subgroup and 15 (6-54) months in the AS subgroup, $p=0.902$. In both groups, inflammatory activity estimated with the help of BASDAI and ASDAS-CRP scales was assessed as high. Most patients had an axial form of SpA or combined axial and peripheral symptoms. The control group did not differ in terms of demographic characteristics and occurrence of traditional risk factors from the groups of patients with PsA and AS (Table I).

In SpA patients (PsA + AS), the level of TG and the atherogenic index (Al) were significantly higher than in the CG, respectively TG in SpA: $116(83-156)$ and in the CG: 91.2 (72.6-134.6) mg/dl, $p=0.018$; Al in SpA: $3.77 \pm 1.26$ and in the CG: $2.58 \pm 1.27, p<0.001$. The level of LDL cholesterol was significantly lower in SpA patients than in the CG, SpA: $109.1 \pm 29.4$ vs. CG: $125.2 \pm 35.9 \mathrm{mg} / \mathrm{dl}$, $p=0.002$.

Patients with PSA were more often overweight than patients with AS: BMI $28.1 \pm 5.2 \mathrm{~kg} / \mathrm{m}^{2} \mathrm{vs} .24 .8 \pm 4.2 \mathrm{~kg} / \mathrm{m}^{2}$, $p=0.005$, CG: $26.4 \pm 4.3 \mathrm{~kg} / \mathrm{m}^{2}$, ns. Dyslipidemia was found significantly more often in patients with PsA: $71.8 \%$ vs. $47.5 \%$ AS, $p=0.028$. In the PsA dyslipidemia group, $48 \%$ had hypercholesterolemia (elevated total and/or LDL cholesterol), 36\% had mixed dyslipidemia, and $16 \%$ had hypertriglyceridemia. In the AS dyslipidemia group, $50 \%$ of patients had hypercholesterolemia, 37.5\% had mixed dyslipidemia, and $12.5 \%$ had isolated hypertriglyceridemia. The percentages of hyperlipidemia types were similar in patients with PSA and AS. Moreover, in

Table I. Characteristics of the study and control groups, including traditional cardiovascular risk factors

\begin{tabular}{|c|c|c|c|c|}
\hline Parameters & $\begin{array}{l}\text { PsA (1) } \\
n=39\end{array}$ & $\begin{array}{l}\text { AS (2) } \\
n=40\end{array}$ & $\begin{array}{c}\text { CG } \\
n=88\end{array}$ & $p$ \\
\hline Female gender, $[n(\%)]$ & $21(53.9)$ & $12(30.0)$ & $42(47.7)$ & $\begin{array}{c}0.076 \text { (overall test, F) } \\
1 \text { vs. CG: } 0.525 \\
2 \text { vs. G: } 0.050 \\
1 \text { vs. } 2: 0.032\end{array}$ \\
\hline Age [years], mean $\pm S D$ & $45.1 \pm 9.6$ & $40.3 \pm 9.5$ & $42.3 \pm 8.1$ & $\begin{array}{c}0.056 \text { (overall test, F) } \\
1 \text { vs. CG: } 0.240 \\
2 \text { vs. CG: } 0.449 \\
1 \text { vs. } 2: 0.045\end{array}$ \\
\hline $\mathrm{BMI}\left[\mathrm{kg} / \mathrm{m}^{2}\right]$, mean $\pm \mathrm{SD}$ & $28.1 \pm 5.2$ & $24.8 \pm 4.2$ & $26.4 \pm 4.3$ & $\begin{array}{c}0.008 \text { (overall test, F) } \\
1 \text { vs. CG: } 0.138 \\
2 \text { vs. CG: } 0.239 \\
1 \text { vs. 2: } 0.005\end{array}$ \\
\hline $\mathrm{BSA}\left[\mathrm{m}^{2}\right]$, mean $\pm \mathrm{SD}$ & $1.98 \pm 0.25$ & $1.91 \pm 0.23$ & $1.97 \pm 0.26$ & $\begin{array}{c}0.446 \text { (overall test, F) } \\
1 \text { vs. CG: } 0.957 \\
2 \text { vs. CG: } 0.548 \\
1 \text { vs. } 2: 0.464\end{array}$ \\
\hline Dyslipidemia, $[n(\%)]$ & $28(71.8)$ & $19(47.5)$ & $48(59.3)$ & $\begin{array}{l}1 \text { vs. CG: } 0.182 \\
2 \text { vs. CG: } 0.221 \\
1 \text { vs. } 2: 0.028\end{array}$ \\
\hline $\mathrm{CRP}[\mathrm{mg} / \mathrm{l}]$ & $\begin{array}{c}8.2 \\
(4.0-15.0)\end{array}$ & $\begin{array}{c}13.5 \\
(5.0-28.5)\end{array}$ & $\begin{array}{c}2,2 \\
(1.2-2,6)\end{array}$ & $\begin{array}{c}1 \text { vs. } 2: 0.161 \\
1 \text { vs. CG: } 0.0017 \\
2 \text { vs. CG: }<0.001\end{array}$ \\
\hline Low physical activity, $[n(\%)]$ & $27(69.2)$ & $29(72.5)$ & NA & 1 vs. 2: 0.749 \\
\hline Smoking, $[n(\%)]$ & $13(33.3)$ & $17(42.5)$ & $32(36.4)$ & 1 vs. 2: 0.401 \\
\hline Family history of cardiovascular diseases, $[n(\%)]$ & $4(10.3)$ & $2(5.0)$ & NA & 1 vs. $2: 0.431$ \\
\hline
\end{tabular}

AS - ankylosing spondylitis, BMI - body mass index, BSA - body surface area, CG - control group, NA - not available, PSA - psoriatic arthritis. 
Table II. Results of tests for cholesterol and lipid fractions in venous plasma in groups of patients with psoriatic arthritis and ankylosing spondylitis, and in the control group

\begin{tabular}{|c|c|c|c|c|}
\hline Lipids & $\begin{array}{l}\text { PsA (1) } \\
n=39\end{array}$ & $\begin{array}{l}\text { AS (2) } \\
n=40\end{array}$ & $\begin{array}{c}\text { CG } \\
n=88\end{array}$ & $p$ \\
\hline $\mathrm{CHOL}[\mathrm{mg} / \mathrm{dl}]$, mean $\pm \mathrm{SD}$ & $198.6 \pm 38.3$ & $188.0 \pm 39.0$ & $202.8 \pm 40.5$ & $\begin{array}{l}0.161 \text { (overall test, F) } \\
1 \text { vs. CG: } 0.844 \\
2 \text { vs. CG: } 0.136 \\
1 \text { vs. } 2: 0.470\end{array}$ \\
\hline $\mathrm{LDL}[\mathrm{mg} / \mathrm{dl}]$, mean $\pm \mathrm{SD}$ & $115.1 \pm 28.6$ & $103.2 \pm 29.8$ & $125.2 \pm 35.9$ & $\begin{array}{c}0.003 \text { (overall test, F) } \\
1 \text { vs. CG: } 0.261 \\
2 \text { vs. CG: } 0.002 \\
1 \text { vs. } 2: 0.248\end{array}$ \\
\hline $\mathrm{HDL}[\mathrm{mg} / \mathrm{dl}]$, mean $\pm \mathrm{SD}$ & $51.2 \pm 14.5$ & $58.5 \pm 16.1$ & $59.4 \pm 15.9$ & $\begin{array}{c}0.024 \text { (overall test, F) } \\
1 \text { vs. CG: } 0.021 \\
2 \text { vs. CG: } 0.951 \\
1 \text { vs. 2: } 0.103\end{array}$ \\
\hline Triglycerides [mg/dl], median (Q1-Q3) & $\begin{array}{c}117 \\
(83-190)\end{array}$ & $\begin{array}{c}110.0 \\
(83-148)\end{array}$ & $\begin{array}{c}91.2 \\
(72.6-134.6)\end{array}$ & $\begin{array}{l}0.038 \text { (overall test, F) } \\
1 \text { vs. CG: } 0.022 \\
2 \text { vs. CG: } 0.088 \\
\text { 1 vs. } 2: 0.393\end{array}$ \\
\hline Atherogenic Index $\mathrm{CHOL} / \mathrm{HDL}$, mean $\pm \mathrm{SD}$ & $4.13 \pm 1.3$ & $3.43 \pm 1.11$ & $2.58 \pm 1.27$ & $\begin{array}{c}<0.0001 \text { (overall test, F) } \\
1 \text { vs. CG: }<0.001 \\
2 \text { vs. CG: } 0.002 \\
1 \text { vs. } 2: 0.052\end{array}$ \\
\hline
\end{tabular}

AS - ankylosing spondylitis, CG - control group, CHOL - total cholesterol, HDL - high-density cholesterol, LDL - low-density cholesterol, PSA - psoriatic arthritis.

Table III. Results of tests for cholesterol and lipid fractions in venous plasma in groups of women and men with psoriatic arthritis and ankylosing spondylitis

\begin{tabular}{|c|c|c|c|c|c|c|}
\hline \multirow[t]{2}{*}{ Lipids } & \multicolumn{3}{|c|}{ Men } & \multicolumn{3}{|c|}{ Women } \\
\hline & $\begin{array}{c}\text { PsA } \\
n=18\end{array}$ & $\begin{array}{c}\text { AS } \\
n=28\end{array}$ & $p$ & $\begin{array}{c}\text { PsA } \\
n=21\end{array}$ & $\begin{array}{c}\text { AS } \\
n=12\end{array}$ & $P$ \\
\hline $\mathrm{CHOL}[\mathrm{mg} / \mathrm{d}]$, mean $\pm \mathrm{SD}$ & $192.1 \pm 38.6$ & $192.9 \pm 37.3$ & 0.943 & $204.1 \pm 38.1$ & $177.1 \pm 42.1$ & 0.069 \\
\hline $\mathrm{LDL}[\mathrm{mg} / \mathrm{dl}]$, mean $\pm \mathrm{SD}$ & $113.6 \pm 1.6$ & $108.9 \pm 26.5$ & 0.595 & $116.4 \pm 26.5$ & $90.4 \pm 33.7$ & 0.020 \\
\hline $\mathrm{HDL}[\mathrm{mg} / \mathrm{dl}]$, mean $\pm \mathrm{SD}$ & $45.7 \pm 13.1$ & $55.3 \pm 16.3$ & 0.043 & $55.9 \pm 14.3$ & $65.6 \pm 13.6$ & 0.066 \\
\hline $\begin{array}{l}\text { Triglycerides } \\
\text { [mg/dl], median (Q1-Q3) }\end{array}$ & $\begin{array}{c}131.5 \\
(98-224)\end{array}$ & $\begin{array}{c}119.0 \\
(93-151)\end{array}$ & 0.385 & $\begin{array}{c}117 \\
(80-133)\end{array}$ & $\begin{array}{c}81.0 \\
(72.5-126)\end{array}$ & 0.261 \\
\hline Atherogenic index $\mathrm{CHOL} / \mathrm{HDL}$ & $4.45 \pm 1.35$ & $3.72 \pm 1.18$ & 0.063 & $3.86 \pm 1.28$ & $2.73 \pm 0.52$ & 0.001 \\
\hline
\end{tabular}

AS - ankylosing spondylitis, CHOL - total cholesterol, HDL - high-density cholesterol, LDL - low-density cholesterol, PSA - psoriatic arthritis.

both groups (PsA and AS), 10.3\% of patients were treated with statins - without a significant difference.

The reduction in total values did not differ between the study groups and the CG. The LDL cholesterol was significantly lower in patients with AS compared to the CG: $103.2 \pm 29.8$ vs. $125.2 \pm 35.9 \mathrm{mg} / \mathrm{dl}, p=0.002$ (Table II).

In contrast, HDL cholesterol was significantly lower in the PSA group compared to the CG: $51.2 \pm 14.5$ vs. $59.4 \pm 15.9 \mathrm{mg} / \mathrm{dl}, p=0.021$. In the examined groups, the concentration of TG: PsA was higher: 117 vs. 91.2; AS: 110.0 vs. $91.2 \mathrm{mg} / \mathrm{dl}, p=0.038$. Values of the atherogenicity index $(\mathrm{Al})$ were significantly higher in the examined groups, respectively: $4.13 \pm 1.3$ vs. $2.58 \pm 1.27$, $3.43 \pm 1.11$ vs. $2.58 \pm 1.27, p<0.0001$ (Table II).

In men with PsA, significantly lower, $p=0.043$, HDL cholesterol levels were found than in men with AS. In women with PsA compared to women with AS, considerably higher levels of LDL cholesterol were found, $p=0.020$, and significantly higher Al values, $p=0.001$ (Table III).

Additionally, there were significant differences in C-reactive protein (CRP) concentrations between SpA, PsA and CG, i.e. 8.2 mg/l (5.0-15.0) in PsA, 13.5 mg/l (5.028.5) in AS and $2.2 \mathrm{mg} / \mathrm{l}(1.20-2.60)$ in the CG, $p=0.0017$. 
There was a strong negative correlation between CRP levels and HDL cholesterol levels in patients with PSA, rho $=0.42, p=0.013$. Mean SCORE value for all the SpA group was $2.33 \%$, for PSA patients 2.3 and for AS patients $2.38 \%$, which results in moderate 10 -year risk of death from CVD. Worse lipid profile parameters in PsA patients were more connected with higher BMI (related to worse metabolic profile) than with the activity of PsA itself.

\section{Discussion}

In the studied groups of patients with SpA, lipid changes were not associated with high serum lipid levels (young study population, relatively low BMI, no patients with diabetes), while atherogenic dyslipidemia occurred. In inflammatory diseases, a decrease in total cholesterol as well as LDL and HDL cholesterol and an increase in TG are observed $[6,7]$.

The "lipid paradox" in which, despite the reduced concentration of total cholesterol and LDL cholesterol, there is a higher cardiovascular risk, has been documented in patients with rheumatic arthritis. Qualitative changes in HDL cholesterol are also found in patients with SpA. The incidence of dyslipidemia is 1.2 times higher than in the general population [17].

The results of the analysis do not strictly show homogeneous lipid disorders in young patients $(<50$ years old) with PSA and AS, despite similar rates of dyslipidemia. The group of patients with PsA was older, the patients' body weight was higher, women constituted a more substantial proportion and significantly more patients had dyslipidemia compared to the group of patients with AS. In the group with PsA compared to AS, a more atherogenic profile of lipid disorders was found: significantly higher TG values, lower HDL cholesterol values and higher values of the atherogenicity index (AI).

In the Moka et al. [6] study and in the CORRONA registry, hypertriglyceridemia occurred in $21 \%$ and $38 \%$ of patients, respectively, i.e., significantly more often than in the general population [18]. In the current study, the overall incidence of hypertriglyceridemia (mixed hyperlipidemia and isolated hypertriglyceridemia) was 36.1\% (PsA) and $22.2 \%$ (AS), which is consistent with the results of the above studies, despite younger patients in the study group being present. Lower HDL cholesterol levels were observed in $36 \%$ of patients with PsA according to data from the CORRONA registry and 33\% in the Moka analysis $[6,18]$. It is pointed out that the reduced HDL level may be the effect of, among other factors, CRP activity, which promotes adverse changes in lipoprotein composition [19].

In the present study, HDL cholesterol levels were reduced in $22.2 \%$ of patients with SpA. In men with PsA the average $\mathrm{HDL}$ level was $45.7 \pm 13.1 \mathrm{mg} / \mathrm{dl}$ and was lower than in patients with AS $(55.3 \pm 16.3 \mathrm{mg} / \mathrm{dl}, p=0.0434)$, but remained close to the general population of the NATPOL study: $45.8 \mathrm{mg} / \mathrm{dl}$. In women with PsA, the average HDL level was $55.9 \pm 14.3 \mathrm{mg} / \mathrm{dl}$ and was lower than in patients with AS $(65.6 \pm 13.6)$, but the difference was not significant, and also remained close to the general population from the NATPOL study: $54.1 \mathrm{mg} / \mathrm{dl}$. However, the analysis of the entire group of patients with PSA showed a strong correlation between the occurrence of elevated CRP values and decreased HDL cholesterol levels, suggesting the role of the inflammatory process in the development of dyslipidemia. A similar relationship was demonstrated by Tam et al. [20].

According to data from the CORRONA registry, as many as $60 \%$ of patients with PsA had an Al value above 3.5 [18]. The mean Al in the study group was $4.13 \pm 1.3$ and was significantly higher than in the CG. Similar to the Moka et al. study [6], a relationship between Al values and inflammation indexes (BASDAI, ASDAS-CRP, (RP) was not demonstrated. This may be due to the fact that CRP levels are elevated only in $40-50 \%$ of patients with PSA, despite the inflammatory activity of the disease, and due to the small size of the study group.

Based on the meta-analysis of the conducted studies, it was found that patients with AS with high inflammatory activity, BASDAI > 4, compared to the general population, had lower levels of $\mathrm{CHOL}, \mathrm{HDL}$ cholesterol and TG. A meta-analysis of similar studies did not show a reduction in LDL cholesterol [21]. In the present study, in patients with AS, in contrast to patients with PSA, no relationship was found between the values of individual cholesterol fractions and inflammation indicators. The mean CHOL concentration in patients with AS was 188.0 $\pm 39.0 \mathrm{mg} / \mathrm{dl}$ in the study.

Similar values were presented by van Eijk et al. [5], whose research included patients corresponding to the group currently analyzed in terms of age and disease activity according to the BASDAI index. Like Gupta et al. [9], we did not find a significant reduction in HDL cholesterol compared to the CG. The Al estimated in our patients was $3.43 \pm 1.11$ and was significantly higher than in the CG. In the studies conducted so far, the authors reported an increased value of Al, but it was not compared with a properly selected CG: in the study of van Eijk et al. [5] it was 3.89, and van Halm et al., 3.1-5.5 [7]. Depending on the groups tested, the levels of TG and LDL cholesterol were elevated or decreased in AS patients. In our study, the average LDL cholesterol value was $103.2 \pm 29.8 \mathrm{mg} / \mathrm{dl}$ and was significantly lower than in the CG. A similar relationship was identified by Gupta et al. (LDL 80.96 $\pm 21.66 \mathrm{mg} / \mathrm{dl}$ ) [9].

In studies of patients treated with TNF- $\alpha$ antagonists, in addition to reducing inflammation parame- 
ters, an increase in HDL, total cholesterol and LDL levels was also observed [5, 22]. Biological treatment also had a positive effect on the HDL molecule composition, while the atherogenicity index values were not significantly changed [5]. The mean TG concentration in the examined group of patients with AS was 110 (83-148) $\mathrm{mg} / \mathrm{dl}$ and was not substantially higher than in the CG. In the study by Choe et al. [23], TG concentration was also insignificantly higher $(118.5 \mathrm{mg} / \mathrm{dl})$ than in the CG. In the Gupta et al. study [9], the TG level in AS patients was even lower than in the CG $(93.65 \pm 6.18 \mathrm{mg} / \mathrm{dl})$. The differences in the values obtained cannot be explained by the age of the respondents or activity and duration of the disease.

Based on previous reports and our own results, it seems that in the group of patients with AS, changes in plasma lipid levels are less marked than in patients with PsA and may have a smaller impact on the occurrence of atherosclerosis.

At the present stage of knowledge, it is also difficult to unequivocally assess the significance of atherogenic dyslipidemia (low HDL levels, higher TG levels) being more frequently observed in patients with PsA given the widely recognized high LDL cholesterol levels as a strong risk factor for CVD and the main goal of lipid-lowering treatment. The problem of the role of dyslipidemia in patients with PSA and AS remains complex and further research is needed, taking into account potential therapeutic interventions. Therefore, not only CVD prevention aimed at reducing traditional risk factors but, above all, close control of the inflammatory process in patients with PsA and AS seems to be necessary.

The risk of death in the group of patients with SpA, according to Agca et al., is 1.9 times higher than in the general population [2]. Cardiological complications account for $40 \%$ of deaths [24].

An additional problem is the fact that both PsA and AS may occur before the age of 16; they include $0.7-1.2 \%$ of Caucasian people. They are referred to as juvenile spondyloarthropathies, in addition to Reiter's syndrome, arthritis associated with immune-related intestinal diseases, and arthritis associated with trailer inflammation tendons [25]. The causes of increased cardiovascular risk are seen in the additive effects of traditional risk factors, inflammatory processes and pharmacotherapy. Persistent stimulation of the immune system in patients with SpA causes a chronic inflammatory process, and the cells and inflammatory mediators involved in it may affect endothelial dysfunction observed in these patient groups [26]. By analogy with rheumatoid arthritis, the role of CRP is indicated, which interacts with pro-inflammatory cytokines in the formation and subsequent de- stabilization of atherosclerotic plaques. The inflammatory process in patients with SpA is particularly active within the vessels [17].

Comparison of the incidence of traditional risk factors in the SpA group with a general representative population was based on the results of the NATPOL 2011 study (the study included people between 18 and 79 years of age) [27]. In the group of patients with SpA, there was no significant difference between the incidence of hypercholesterolemia (increased total cholesterol and/or statin or fibrate use) in the group of patients with PsA, and the NATPOL 2011 population: 53.8\% vs. $61 \%, p=0.4583$. However, in the group of patients with AS, the incidence of hypercholesterolemia defined in this way was significantly lower than in the NATPOL 2011 population: $35 \%$ vs. $61 \%, p=0.001$ [27].

\section{Clinical implications}

Due to the more frequent occurrence of changes in the cardiovascular system and low accuracy of scales assessing the cardiovascular risk in patients with spondyloarthropathies, it seems reasonable to periodically perform cardiological assessment of patients with spondylopathy shortly after diagnosis of rheumatological disease, combined with additional tests. Atherogenic dyslipidemia may be responsible for the increased cardiovascular risk: low HDL cholesterol and elevated TG, which may result from an ongoing inflammatory process.

\section{Study limitations}

Potential study limitations include the retrospective nature of the CG and the combined analysis of patients with axial and peripheral spondyloarthropathy. Psoriatic arthritis patients were not assessed for psoriasis by PASI (Psoriasis Area and Severity Index). The groups were not homogeneous in terms of treatment of the underlying disease, which was not included in the analyses.

\section{Conclusions}

In young patients with spondyloarthropathies, inflammatory factors significantly influence dyslipidemia patterns, which result in higher TG and lower LDL cholesterol levels. In patients with PSA, more evident atherogenic dyslipidemia, i.e., significantly decreased HDL cholesterol and increased TG levels, were diagnosed, than in patients with ankylosing spondylitis.

The authors declare no conflict of interest. 


\section{References}

1. Rudwaleit M, van der Heijde D, Landewé R, et al. The Assessment of SpondyloArthritis International Society classification criteria for peripheral spondyloarthritis and for spondyloarthritis in general. Ann Rheum Dis 2011; 70: 25-31, DOI: 10.1136/ard.2010.133645.

2. Agca R, Heslinga SC, van Halm VP, Nurmohamed MT. Atherosclerotic cardiovascular disease in patients with chronic inflammatory joint disorders. Heart 2016; 102: 790-795, DOI: 10.1136/heartjnl-2015-307838.

3. Peters MJ, van der Horst-Bruinsma IE, Dijkmans BA, Nurmohamed MT. Cardiovascular risk profile of patients with spondyloarthropathies, particularly ankylosing spondylitis and psoriatic arthritis. Semin Arthritis Rheum 2004; 34: 585-592, DOI: 10.1016/j.semarthrit.2004.07.010.

4. Bakland G, Gran JT, Nossent JC. Increased mortality in ankylosing spondylitis is related to disease activity. Ann Rheum Dis 2011; 70: 1921-1925, DOI: 10.1136/ard.2011.151191.

5. van Eijk IC, de Vries MK, Levels JH, et al. Improvement of lipid profile is accompanied by atheroprotective alterations in high-density lipoprotein composition upon tumour necrosis factor blockade: a prospective cohort study in ankylosing spondylitis. Arthritis Rheum 2009; 60: 1324-1330, DOI: 10.1002/art.24492.

6. Moka CC, Ko GT, Ho LY, et al. Prevalence of atherosclerotic risk factors and the metabolic syndrome in patients with chronic inflammatory arthritis. Arthritis Care Res 2011; 63: 195-202, DOI: 10.1002/acr.20363.

7. van Halm VP, van Denderen JC, Peters MJ, et al. Increased disease activity is associated with a deteriorated lipid profile in patients with ankylosing spondylitis. Ann Rheum Dis 2006; 65: 1473-1477, DOI: 10.1136/ard.2005.050443.

8. Malesci D, Niglio A, Mennillo GA, et al. High prevalence of metabolic syndrome in patients with ankylosing spondylitis. Clin Rheumatol 2007; 26: 710-714, DOI: 10.1007/s10067006-0380-5.

9. Gupta N, Saigal R, Goyal L, et al. Carotid intima-media thickness as a marker of atherosclerosis in ankylosing spondylitis. Int J Rheumatol 2014; 2014: 839135, DOI: 10.1155/2014/ 839135.

10. Spanakis E, Sidiropoulos P, Papadakis J, et al. Modest but sustained increase of serum high-density lipoprotein cholesterol levels in patients with inflammatory arthritides treated with infliximab. J Rheumatol 2006; 33: 2440-2446.

11. Steyers CM, Miller FJ Jr. Endothelial dysfunction in chronic inflammatory diseases. Int J Mol Sci 2014; 15: 11324-11349.

12. Rudwaleit $M$, van der Heijde D, Landewé R, et al. The development of Assessment of SpondyloArthritis international Society classification criteria for axial spondyloarthritis (part II): validation and final selection. Ann Rheum Dis 2009; 68 777-783, DOI: 10.1136/ard.2009.108233.

13. Rudwaleit $M$, van der Heijde $D$, Landewé $R$, et al. The Assessment of SpondyloArthritis International Society classification criteria for peripheral spondyloarthritis and for spondy- loarthritis in general. Ann Rheum Dis 2011; 70: 25-31, DOI: 10.1136/ard.2010.133645.

14. Taylor W, Gladman D, Helliwell P, et al. CASPAR Study Group. Classification criteria for psoriatic arthritis: development of new criteria from a large international study. Arthritis Rheum 2006; 54: 2665-2673, DOI: 10.1002/art.21972.

15. Van der Linden S, Valkenburg HA, Cats A. Evaluation of diagnostic criteria for ankylosing spondylitis. A proposal for modification of the New York criteria. Arthritis Rheum 1984; 27 : 361-368, DOI: 10.1002/art.1780270401.

16. Zdrojewski T, Jankowski P, Bandosz P, et al. Nowa wersja systemu oceny ryzyka sercowo-naczyniowego i tablic SCORE dla populacji Polski. Kardiol Pol 2015; 73: 958-961, DOI: 10.5603/ KP.2015.0182.

17. Han C, Robinson DW Jr, Hackett MV, et al. Cardiovascular disease and risk factors in patients with rheumatoid arthritis, psoriatic arthritis, and ankylosing spondylitis. J Rheumatol 2006; 33: 2167-2172.

18. Labitigan M, Bahče-Altuntas A, Kremer JM, et al. Higher rates and clustering of abnormal lipids, obesity, and diabetes mellitus in psoriatic arthritis compared with rheumatoid arthritis. Arthritis Care Res (Hoboken) 2014; 66: 600-607, DOI: 10.1002/acr.22185.

19. Khovidhunkit W, Kim MS, Memon RA et al. Effects of infection and inflammation on lipid and lipoprotein metabolism: mechanisms and consequences to the host. J Lipid Res 2004; 45: 1169-1196, DOI: 10.1194/jlr.R300019-JLR200.

20. Tam LS, Tomlinson B, Chu TT, et al. Cardiovascular risk profile of patients with psoriatic arthritis compared to controls - the role of inflammation. Rheumatology (Oxford) 2008; 47: 718-723, DOI: 10.1093/rheumatology/ken090.

21. Mathieu S, Gossec L, Dougados M, Soubrier M. Cardiovascular profile in ankylosing spondylitis: a systematic review and meta-analysis. Arthritis Care Res (Hoboken) 2011; 63: 557-563, DOI: 10.1002/acr.20364.

22. Heslinga SC, Peters MJ, Ter Wee MM, et al. Reduction of Inflammation Drives Lipid Changes in Ankylosing Spondylitis. J Rheumatol 2015; 42: 1842-1845, DOI: 10.3899/jrheum. 150193.

23. Choe JY, Lee MY, Rheem I, et al. No differences of carotid intima-media thickness between young patients with ankylosing spondylitis and healthy controls. Joint Bone Spine 2008; 75 : 548-553.

24. González-Gay MA, González-Juanatey C. Inflammation and lipid profile in rheumatoid arthritis: bridging an apparent paradox. Ann Rheum Dis 2014; 73: 1281-1283, DOI: 10.1136/ annrheumdis-2013-204933.

25. Rutkowska-Sak L. Słowińska S, Żuber Z. Młodzieńcze spondyloartropatie. Ann Acad Med Stetin 2010; 56, suppl 1: 29-33.

26. Sari I, Okan T, Akar S, et al. Impaired endothelial function in patients with ankylosing spondylitis. Rheumatology (Oxford) 2006; 45: 283-286, DOI: 10.1093/rheumatology/kei145.

27. Zdrojewski T, Solnica B, Cybulska B, et al. Prevalence of lipid abnormalities in Poland. The NATPOL 2011 survey. Kardiol Pol 2016; 74: 213-223, DOI: 10.5603/KP.2016.0029. 